\title{
La red social Facebook como dispositivo de control. Una mirada desde la filosofía de Foucault.
}

The social network Facebook as control device. A look from the Foucault philosophy

\author{
Celina Arredondo Rubio \\ Maestra en Estudios Filosóficos. Universidad de Guadalajara (MÉXICO) \\ CE: celina.aru@gmail.com
}

DOI: $\underline{10.32870 / \text { sincronia.axxiv.n77.8a20 }}$

Esta obra está bajo una Licencia Creative Commons Atribución-NoComercial 4.0 Internacional

$\mathrm{BY} \cdot \mathrm{NC}$

Recibido: 22/08/2019

Revisado: $02 / 10 / 2019$

Aprobado: 05/11/2019

\section{RESUMEN}

La irrupción de la tecnología informática y las redes sociales principalmente facebook originó cambios que comenzaron a empoderar a cada individuo de la sociedad, otorgando un espacio para expresarse, manifestarse y participar. Facebook como la red social más importante y utilizada a nivel mundial (Asociación de internet,2018) juega un papel importante en la sociedad, interviniendo en su cotidianeidad de manera sutil, contribuyendo en la práctica de un control que se ejerce hacia el mismo sujeto que la utiliza.

En este artículo se define el concepto de dispositivo de control y panóptico según Foucault, también se analiza la relación de la red social Facebook como dispositivo de control y sistema disciplinario. El propósito es mostrar cómo el control y el poder migran y se adaptan conforme a la evolución de las tecnologías de información, manipulando de manera subjetiva a través de deseos, introducidos de manera inconsciente e imperceptible. Esto genera un problema aún más complicado, la evolución de la tecnología hasta el punto de un "Control De Todo". Es un control sutil, inmerso 
bajo programación informática, con matices de deseo, ingenuidad y practicidad para el individuo, aceptando el control voluntariamente.

Palabras clave: Dispositivo de control. Panóptico. Red social Facebook. Foucault.

\section{ABSTRACT}

The introduction of computer technology and social networks mainly Facebook caused a change that gradually have empowered gradually individuals in society, providing a space to speak, express, manifest and participate. Facebook as the most important social network used worldwide (Internet Association, 2018) plays an important role in society, intervening in its daily life in a meaningful way, contributing to the practice of a control that is excerted upon the very subjects that resort to it.

In this article the concept of a control devices and panoptic is defined according to Foucault. An analysis of the social network Facebook is carried out as a control device and disciplinary system. The purpose is to show how control and power migrate and adapt according to the evolution of electronic information and communication technology, subjectively manipulating society through desires, unconsciously and imperceptibly introduced. This generates an even more complicated problem, namely the evolution of technology to the point of a "Control of Everything." It is a subtle control, immersed under computer programming, with nuances of desire, ingenuity and practicality for the individual, accepting control voluntarily.

Keywords: Control device. Panoptic. Social network Facebook. Foucault.

\section{Introducción}

El presente trabajo tiene el objetivo de relacionar la función del poder disciplinado, el panóptico y el dispositivo de control desde el enfoque de Michel Foucault con la red social Facebook. Se clarifican los conceptos y la doble función de la plataforma Facebook: la primera como un medio de información y expresión libre, y la segunda como un mecanismo con propósitos de control. Para el tratamiento de este problema se recurre a la teoría de Foucault, quien en su tiempo estudió instituciones, tales como hospitales psiquiátricos, reclusorios o escuelas, descubriendo la existencia 
de dispositivos de control en la sociedad. Sus herramientas conceptuales pueden aplicarse actualmente para analizar las redes sociales, las cuales se han convertido en espacios de vigilancia, manipulación y de control. Es decir, se ha transitado del control físico al control virtual.

La diferencia entre el control físico y el control virtual podría ser que este último es aún más peligroso que el primero. A pesar de que las redes sociales han contribuido con la expansión de algunos derechos del individuo, la misma expansión de derechos se ejecuta al mismo tiempo que sus riesgos, ejerciendo el control como dispositivos, y las redes sociales están siendo utilizadas como un medio de poder practicado por todos y para todos. El individuo es el que aporta ese poder, ya que todos pueden observar y al mismo tiempo ser observados, de esta manera todos contribuyen y se convierten en colaboradores. Es un poder intercalado; del observado al que observa, y cualquier sujeto es potencialmente participe, de esta manera todos forman parte del llamado panóptico.

A pesar de que Foucault reconstruye los conceptos de dispositivo de control y panóptico mucho antes del uso masivo de internet y de la existencia de las redes sociales, la estructura de su definición encaja con las nuevas formas de control que actualmente se implementan en el espacio virtual. Los conceptos que expone Foucault explican claramente la manera en que funciona el poder y el control. El panorama utópico de vigilar, controlar y castigar se está edificando a través de las redes sociales.

\section{Sistemas disciplinados, panópticos y dispositivos}

En El Poder Psiquiátrico, Foucault (2005a), se encarga de hacer una distinción entre dos formas constantes de ejercer el poder, poder soberano y poder disciplinario. La condición de soberanía es una relación de poder que liga al soberano y al súbdito según un par de relaciones asimétricas, por un lado, la sustracción, y por otro, el gasto. El soberano sustrae productos, cosechas, objetos fabricados, armas, fuerza de trabajo y les ofrece un servicio de protección o religioso. Para que esta relación de soberanía se mantenga efectiva es necesario el complemento de la violencia y las amenazas. Por otra parte, Foucault opone al poder disciplinario con el poder de soberanía. El poder 
disciplinario no sustrae el producto o una parte del tiempo, sino una captura total y exhaustiva del cuerpo, de los gestos y del comportamiento del individuo. El poder disciplinario implica un control constante, el estar perpetuamente bajo la mirada de alguien, como entidad observada. Este filósofo resume el poder disciplinario con un carácter panóptico, como una visibilidad absoluta y constante:

El poder disciplinario es individualizante porque ajusta la función sujeto a la singularidad somática por intermedio de un sistema de vigilancia y escritura o un sistema de panoptísmo pangráfico que proyecta por detrás de la singularidad somática, como su prolongación a su comienzo, un núcleo de virtualidades, un psique, y establece además, la norma como principio de partición y la normalización como prescripción universal para todos los individuos (Foucault, 2005a p.77).

El panóptico parte del siglo XVIII, Jeremy Bentham (Foucault, 1979) formuló la idea del panóptico, en el cual se requerirían menos empleados que vigilaran a los presos. El panóptico es un tipo de arquitectura para uso penitenciario, construido de forma circular con celdas individuales y una torre justo en el centro. El objetivo del panóptico es observar a todos los presos sin que ellos se den cuenta, creando un estado consciente de visibilidad absoluta, y de poder ver sin ser percibidos. El panóptico establece una situación de poder en la cual el mismo observado es quien aporta ese poder.

Foucault toma la idea del panóptico como un dispositivo de vigilancia implementado en todo tipo de instituciones (escuelas, fabricas, hospitales) con el fin de establecer sistemas disciplinarios. En su libro Vigilar y Castigar Foucault (2005b) menciona que el panóptico funciona como un modelo generalizable que define las relaciones de poder en la vida cotidiana del hombre. De esta manera las escuelas, hospitales, cárceles y la sociedad rigen y moldean el pensamiento, lo construyen bajo normas subjetivas implantadas creando ciudadanos que pueden ser observados, conformando sociedades disciplinarias.

El esquema panóptico es ideal para imponer conductas a una sociedad, una forma de hacer funcionar las relaciones de poder. El poder omnisciente y la vigilancia crean en el individuo 
autocontrol en la manera de comportarse; su eficacia se solidifica en la acción del ver sin ser visto. Para Foucault, el poder del panóptico crea sujetos automatizados e individualizados, que son observados, no obstante, desconociendo al vigilante. El dispositivo borra singularidades e impone homogeneización, tiene la posibilidad de organizar, clasificar, utilizar, reconocer a sus observadores para garantizar el control.

El panóptico es una máquina que crea y sostiene una relación de poder sin relevancia en el sujeto que lo ejerce. Para Foucault (2005b) el panóptico puede ser utilizado como una máquina para crear experiencias y modificar el comportamiento de los individuos, experimentar con ellos, analizar las transformaciones y obtener información.

El fin del panoptísmo son las relaciones de disciplina y es el principio general de la nueva anatomía política. Foucault sitúa las disciplinas desde dos imágenes extremas; un lado, está la disciplina-bloqueo, que se refiere a las instituciones cerradas, con funciones negativas como detener el mal o romper comunicaciones como la cuarentena. Y el otro sitúa al panoptísmo, la disciplina-mecanismo, un dispositivo que mejora el funcionamiento del poder, volviéndolo más rápido, ágil, ejerciendo coerción de manera sutil hacia la sociedad. De este modo la formación de una sociedad disciplinada está originando una productividad alta, centralización, aceptación de las normas y pensamientos impuestos por quien tiene el poder.

Con el surgimiento del poder disciplinario Foucault (2002) en Historia de la Sexualidad, sitúa el deseo como núcleo del dispositivo de la sexualidad, donde el deseo orienta el comportamiento del individuo, describiendo su función como dispositivo de poder:

La sociedad de la sexualidad se caracteriza por difundir mecanismos de poder que se dirigen al cuerpo y la vida, uniendo la noción de cuerpo y población, intenta reforzar la especie, su vigor, su capacidad de dominar o su aptitud para ser utilizada a través de nociones de progenitura, raza, porvenir de especie, vitalidad del cuerpo social (Godínez, 2018 p.50). 
Ahora bien, para comprender mejor el concepto de dispositivo, el propio Foucault señala:

Lo que trato de situar bajo ese nombre es, en primer lugar, un conjunto decididamente heterogéneo, que comprende discursos, instituciones, instalaciones arquitectónicas, decisiones reglamentarias, leyes, medidas administrativas, enunciados científicos, proposiciones filosóficas, morales, filantrópicas; en resumen: los elementos del dispositivo pertenecen tanto a lo dicho como a lo no dicho. El dispositivo es la red que puede establecerse entre estos elementos (Ornicar, 1977, p 4).

El dispositivo es, con ello, la relación entre el poder y el discurso para producir subjetividades, verdades/discursos para producir identidades. Podría decirse que el dispositivo es la amalgama que conforma los elementos y las relaciones que hacen que funcione el control, en pocas palabras es la red. La producción de subjetividades va acorde a la conveniencia de quien ejerce ese poder. La economía como principal contenedor de control en esta época y a través del dispositivo convierte a individuos con subjetividades que producen deseos. Está presente en todas las relaciones humanas e interviene de manera subjetiva en la interacción entre individuos. Esta red está conformada por un saber/poder (2004). Pero ¿cómo actúa el saber para articular el poder? Para Foucault el saber es un discurso de lo que un grupo determinado comparte, definiendo lo que es verdad y lo que no. Foucault considera al poder como la posibilidad de modificar las acciones presentes o posibles del otro. En El Nacimiento de la Clínica, Foucault (2004) ejemplifica con el caso de la función del médico en un hospital, en el cual se ejerce este poder/saber, en este caso médico-enfermo, y es respaldado por el discurso que la misma institución valida. Esta misma experiencia se da, en cualquier relación, maestro-alumno, patrón-obrero, etc.

El Estado, la iglesia, la familia, las escuelas, los hospitales, o la misma sociedad funcionan entre ellas bajo este poder/saber, y es posible afirmar que las tecnologías de la información tienen la misma función. Existe un discurso que se presenta y que controla bajo entornos determinados, estructurando comportamientos, deseos y formas de ser. El discurso de lo dicho y lo no dicho es la 
diferencia entre lo que se escucha y se establece, lo subjetivo, que es la comprensión de uno mismo, la vida, las relaciones, dominando el comportamiento, creando maneras de pensar que pueden segregar, aceptar o intervenir en las decisiones.

En Los Anormales, Foucault (2000) sostiene que la razón ha sido instaurada para dominar a los hombres y analiza de cerca el funcionamiento de los manicomios. La sociedad disciplinaria que se hace llamar la sociedad racional segrega a los anormales de los normales, en este caso, los locos. De esta manera bajo el poder que la misma institución otorga se domina al hombre, le impone una verdad, lo controla, y el sujeto aprende este discurso para auto-controlarse. Los dispositivos de control se expresan a través del lenguaje que definen el discurso, y este aprueba o desaprueba ciertas prácticas o comportamientos que terminan estereotipando conceptos de lo que es bueno o lo que es malo según quien controla.

\section{El dispositivo Facebook}

Para elaborar una idea más clara de los conceptos de dispositivo de control, sistema disciplinario y panóptico se comienza distinguiendo entre las funciones de control de Facebook: Como red social y como empresa global. Facebook como red social, es un micro-panóptico con individuos que vigilan y se auto-vigilan. Con usuarios (empresas, organizaciones religiosas o políticas, personajes influyentes) que tratan de instaurar tendencias, difundir su propia verdad, vender sueños y felicidad para imponen conductas. Como empresa es un macro-panóptico con sus mega estructuras informáticas que tienen la capacidad de adquirir información de cualquier sujeto o grupo y venderla.

No obstante, esta división, Facebook es un dispositivo de control, no con prohibiciones sino con libertades que sirven para manipular y disciplinar. Para Foucault (2002) los mismos dispositivos de control establecen discursos donde dicen qué es la libertad y después hacen creer que el sujeto es libre, ocultando una estructura de manipulación. De esta manera, Facebook construye identidades, difunde ideas, establece comportamientos, deseos, etc, creando subjetividades que alienan y controlan. 


\section{Facebook como productor de subjetividades. La función del deseo}

El dispositivo tiene diferentes herramientas de control y una de ellas es la subjetividad. Un caso de la subjetividad es la manipulación del deseo, se ofrece la ilusión de felicidad como táctica que convierte al sujeto en un producto del sistema disciplinario. El individuo vive a través de las nuevas tecnologías de la información y comunicación, las redes sociales muestran su modo de vida y el humano disfruta de utilizarlas, de publicar en ellas y compartir cualquier información personal. No obstante, las plataformas de libre expresión y de facilidad de uso y expansión de información podrían operar de maneras tan diversas que ofrezcan una pantalla de entretenimiento en el cual hay procedimientos de manipulación y subjetivación. Las redes sociales ayudan al usuario a informar al mundo la privacidad de su vida, su felicidad, Facebook lo llama: biografía.

¿Cómo produce subjetividades Facebook? Facebook surge desde una cultura norteamericana, con una ideología basada en materialismo, consumismo y deseos. Ahora por medio de esta red social se expande esa forma de pensamiento. Los individuos pertenecientes a esta red desean reconocimiento, desean encontrar satisfacción a través de estos medios. En Facebook el individuo puede compartir cualquier actividad, gustos, pensamientos y le es agradable recibir comentarios y likes por lo que se comparte. De lo contrario, el individuo se siente frustrado, decaído. El deseo de compartir y recibir es la manera de convivir y relacionarse por medio de las redes sociales, su estado de ánimo se ve mejorado, le da felicidad al publicar sus posesiones y actividades. En Facebook las personas comparten fotos del auto último modelo, los lugares a los que viajan o el costoso restaurante que visitan, produciendo envidia, celos, creando un ambiente de deseos y competencia sumergido en un mundo de posesiones y consumismo. Pero, ¿podría decirse que existe una manipulación hacia la sociedad a través del deseo que produce Facebook? René Girard (2009) desarrolló la teoría mimética o mimesis como una teoría de deseos, de competición y conflictos entre los individuos. Mimesis es un concepto que significa imitación, copia. Y coincide perfectamente en la manera en que las personas socializan con otras en redes sociales, en donde la 
competición de likes, de videos virales y los deseos de adquirir bienes materiales dan estatus y son prioridad, ofreciendo la ilusión de felicidad.

Las personas comparten sus capacidades sociales, económicas, políticas, y lo que publican se convierte en una competencia de likes, sin importar si es verdadero lo que publican o si no lo es. Se está creando una sociedad individualista con beneficios particulares. En sociedades individualistas no hay cooperación, ni sociedades con fines colectivos. "Las actuales sociedades neoliberales son sociedades agitadoras del deseo: Grupos constituidos por el deseo, conglomerados de inquietudes deseantes que se contagian mutuamente y se precipitan a un intenso flujo de deseos renovados a diario" (Godínez, 2018. p.135).

Es importante destacar que subjetivamente a través del deseo las redes sociales están ofreciendo la ilusión de felicidad y las formas de control social físico anteriormente ejercidas han migrado al mundo cibernético. Facebook es una herramienta que ofrece subjetivaciones y las personas lo aceptan y acceden a él fácilmente a cambio de un control sutil, imperceptible con ligereza en su función que está interviniendo en las experiencias, la forma de pensar y la toma de decisiones de los individuos. Puede ser que Facebook ofrezca libertad de expresar y producir deseos, sin embargo, una gran cantidad de likes no significa felicidad. Por el contrario, debería de preguntarse qué es lo que se da a cambio al momento de ser parte de una red virtual que ofrece libertad y felicidad gratuitamente. En este caso, el individuo se convierte en mercancía. Facebook a través de internet.org trata de llevar internet de manera gratuita a países de bajos recursos. Pero ¿Cuál sería el propósito y que ganaría Facebook?:

Uno de los problemas de que gobiernos le digan sí a grandes empresas como Google o Facebook en programas como Ceibal o Internet.org, es que su llegada tiene una moneda de cambio que las autoridades parecen ignorar. Detrás de esa "gratuidad" de sus servicios, está la condición de obtener y manipular tus datos personales, hacer perfilamientos de tus hábitos, cambiar las condiciones de su servicio cuando les dé la gana y, al parecer, hasta compartir tu información sin necesariamente respetar el debido proceso cuando se trata de gobiernos como el de Estados Unidos. Y en el particular caso de Internet.org, ni siquiera se 
garantiza el uso de protocolos de seguridad mínimos como el https para evitar intercepciones de información. (Peña, 2015).

Recibir internet gratuitamente e incrementar la cantidad de usuarios de Facebook implica un alto costo que involucra la pérdida de privacidad. La información almacenada de cada sujeto es la mercancía de valor para grandes empresas como Facebook. Esta red social analiza, controla y estabiliza al individuo, mostrándole un mundo de aspiraciones, sueños y éxito. Su función como subjetivación cumple con el trabajo de analizar a cada individuo, le muestra y lo encamina hacia un anhelo que el mismo sistema establece, implementando e influenciando al individuo de que es un deseo naciente de él y no del sistema. El dispositivo de control se implementa en cualquier clase de interacción humana, y el mismo individuo es un dispositivo (García, 2011).

Para dominar hay que producir subjetividades, Facebook produce subjetividades y con sus mismos mecanismos auto-evalúa al individuo para continuar produciendo más subjetividades, Facebook es una ventana grande al consumo, ofreciendo el deseo de tener y de llegar a ser. Define al sujeto a través de deseos, produce y manipula identidades.

Una de las funciones de Facebook es presentarse como una red que hace creer al usuario que es libre, que no hay prohibiciones. Facebook ofrece una ilusión de felicidad, de deseo y bienestar que se propaga a través de la convivencia, es una red social que se auto-legitima, las personas confían en ella, la visualizan como mero entretenimiento, creen la información que encuentran en ella, y están felices de entregar su información y compartirla. Sin embargo, se deben aceptar sus condiciones legales para poder utilizar la aplicación, de lo contrario, no es posible acceder a ella, y este es el primer elemento de control. Despliegan un contrato con decenas de hojas, con letra minúscula, con cláusulas donde se establece el uso que le darán a la información, sin embargo, según análisis realizados (Llamas y Llamas, 2018)., toma alrededor de 11 horas poder leer dichos contratos de principio a fin. De esta manera, el individuo voluntaria y agradecidamente da su consentimiento a la intervención de su privacidad y control. 
Facebook establece mecanismos para actuar como institución que beneficia a quienes pagan por ellos, y existen mecanismos que definen las relaciones de poder en la vida virtual del individuo. Facebook como red social es capaz de dar poder de control al sujeto, a una empresa, grupo o institución de una manera sencilla, rápida, con alcance mundial y a tiempo real. Esta red social está compuesta por millones de personas, preparadas para expresar, difundir y vigilar. El dispositivo de control se desempeña cada vez menos de manera unidireccional y va en múltiples sentidos. Facebook se ha convertido en una herramienta que es capaz de otorgar y ejercer poder a cualquiera. Cualquier usuario de Facebook tiene acceso a información de cualquier persona con una configuración simple de privacidad, los llamados hackers pueden acceder a contraseñas e información de otros usuarios, esparcir virus que vigilan, que rastrean y que roban información (Proceso, 2016). Facebook es un gran conjunto integrado por pequeños conjuntos, y cada uno de ellos tiene la capacidad de ejercer su poder de manera individual o colectiva.

Facebook es dueño de las imágenes y publicaciones que comparte el individuo, y éste le otorga un permiso para usar su nombre con fines comerciales. Por tanto, el individuo se convierte en mercancía. "Producir mercancía y estar en competencia (mimesis) son los dos principios fundamentales de las sociedades posesivas de mercado, organización correspondiente a las sociedades neoliberales" (Godínez, 2018 p. 125). El individuo otorga a Facebook el permiso para instalar cualquier actualización o software al equipo en el que se esté utilizando esa aplicación, con el riesgo de robo de información almacenada. Derrida (2000) en su obra La hospitalidad hace referencia a la pérdida de intimidad a consecuencia de las nuevas tecnologías de la información, las redes sociales han penetrado en la intimidad del sujeto, no existe más un estado íntimo. Se esta vigilado y sujetando al individuo con herramientas que se involucran e intervienen en la cotidianeidad de manera inconsciente. De esta manera Facebook como red, es un dispositivo de control que puede esparcir información y tener la capacidad de vigilar bajo el anonimato. A través de Facebook siguen existiendo instituciones, discursos, relaciones de poder, saber, y control. La diferencia es que este control es aceptado por el mismo usuario. 
Las grandes empresas creadoras de fake News están dedicadas a difundir información estableciendo su propia verdad, Y a través de programación informática pueden llegar a los primeros lugares de aparición y ranking, haciendo creer al individuo la veracidad de la información (Broderick y Arredondo, 2018). No obstante, los videos de ataques, desastres naturales, eventos políticos o religiosos que se dicen son en vivo y que las personas creen reales pueden ser casos de engaños. Con las herramientas como photoshop o edición de videos, el poder de la información puede ser manipulada. Una de las características importantes en el funcionamiento del dispositivo de control en Facebook es que son los mismos usuarios los que tienen el saber y el poder para que siga funcionando el dispositivo, comparten, dan like, crean videos, mensajes de odio, de amor, etc. $\mathrm{Y}$ son ellos mismos quienes legitiman y voluntariamente otorgan y reciben el control. Sin los usuarios la red desaparecería, como muchas otras que se extinguieron por falta de público. Foucault (2005b p. 220) plantea que "No estamos ni sobre las gradas ni sobre la escena, sino en la máquina panóptica dominados por sus efectos de poder que prolongamos nosotros mismos, ya que somos uno de sus engranes". Facebook se está convirtiendo en una red en donde las relaciones y el poder se fortalecen por los mismos usuarios, a tal grado de ser referencia para entrar a un país (BBC, 2017), obtener un trabajo, o sencillamente encontrar pareja.

Facebook como una red social es una plataforma donde los usuarios tienen acceso al poder y al control, y Facebook como empresa posee acceso absoluto a la información de sus usuarios, la cual puede ser vendida a otras empresas, gobiernos, partidos políticos, candidatos presidenciales e incluso a la delincuencia, reforzando su calidad de panóptico.

Existen relaciones de poder y jerarquización dentro de Facebook. Es una empresa que vigila a los usuarios, las páginas, las empresas; inclusive las instituciones gubernamentales. Facebook cuenta con diversas herramientas para adquirir información del individuo, como la raza, el color de piel, las preferencias, su ubicación, su trabajo y todo puede hacerlo con una computadora por medio de algoritmos. Cuando Facebook se instala en una computadora, celular o tableta pide acceso a la cámara, al micrófono, a los contactos, a las fotos y a los videos. Esto quiere decir que la empresa puede tener acceso a cualquier información que esté en el teléfono de un individuo con la 
aplicación instalada. Pueden escuchar o tomar video o fotos de cualquier sujeto, entonces, es una aplicación que puede ver, escuchar, saber actividades, ubicaciones, conversaciones o cualquier información almacenada en un aparato electrónico (Facebook, 2018).

Facebook tiene su infraestructura tecnológica. Quizás la arquitectura no necesariamente hace al panóptico, sino su función. Además, cada mecanismo es propio de su tiempo. Esta herramienta se vale de redes y dispositivos que permiten el monitoreo remoto sin la necesidad de una torre. Su funcionamiento de vigilar, ver sin ser visto, establecer comportamientos, aceptar o segregar individuos, clasificar, organizar y utilizar información pública y privada, cumple con su finalidad de mantener el control. Generar demasiada información transforma las relaciones de convivencia humana e incide en la conducta del sujeto. A través de las nuevas formas de control, el sujeto muestra y da más información de lo que podría parecer, no prestan atención a la información subjetiva que comparten, están dando al controlador más poder sin siquiera saberlo. "La red social es vista como un producto de control de masas sobre las cuales se tiende una manipulación comercial" (Constante, 2013. p 40).

Por medio de la manipulación de información, se instaura un hecho, transformándolo en verdad, lo utiliza como instrumento discursivo de poder, de esta manera controla al sujeto. La confesión de la que habla Foucault en la cual existe un registro, dominio y relaciones de poder hacia el sujeto es ahora la confesión por medio de las redes sociales, el propietario de la información de la Big Data (IBM, 2019), es el que maneja la información, y la subasta para controlar. Las redes sociales se han vuelto parte de la vida cotidiana del sujeto y no solo eso, sino que ahora también se vuelven una necesidad para él. Se han introducido en sus vidas a tal grado que el sujeto acepta sus condiciones y cláusulas para pertenecer a un grupo, sentirse aceptado, se tiene la necesidad de ser reconocido y de ser exitoso. Las necesidades humanas están siendo satisfechas por medio de las redes sociales, les dan sentido a la existencia de las personas sin tomar en cuenta que el sujeto está siendo controlado a través de ellas. 


\section{Conclusiones}

La red social Facebook se desempeña como dispositivo de control y como panóptico, disciplinando al individuo a través de subjetivaciones que ofrecen deseos en su mayoría ajenos él. Observar y analizar el comportamiento es una eficaz forma para adquirir conocimiento acerca del sujeto y de esta manera saber cómo dominarlo. En internet, el Big Data, los algoritmos y bots se encargan de hacer este análisis. El control se ejerce de manera sutil a través del consumo, el deseo y en las redes sociales con su hedonismo, superficialidad y su verdad. De esta manera se establece una sujeción entre la información obtenida (Big data) quien(es) la domina(n) y a quien se le impone. El poder forma saber y produce discursos. El poder lucha para establecer su verdad. Lo que existe al final es esta reinterpretación de la verdad que el poder repite y repite constantemente hasta creerlo.

Las sociedades disciplinadas tienen el discurso instaurado del consumo. Son una cultura de consumo, es una tecno-cultura (Yehya, 2008) social disciplinada para continuar bajo el control aceptándolo ahora por otra vía. La practicidad, la belleza, el consumo, la innovación son los discursos que ordenan al sujeto acerca de cómo se debe vivir y cómo podría ser feliz. Discursos que llegan a él a través de los medios de comunicación que están a su alcance y que son los principales medios en los cuales el sujeto quiere ser parte de ellos. Incluso perdiendo su privacidad y aceptando el control por parte de otros. Alentando sus deseos de querer ser y querer tener, los sujetos se exigen cada vez más a sí mismos, creando sujetos frágiles, indiferentes, individualizados y controlados.

\section{Referencias}

Asociación de Internet (2018). Hábitos de los usuarios de internet en México 2018. Recuperado de:

https://www.asociaciondeinternet.mx/es/component/remository/Habitos-de-Internet/14-

Estudio-sobre-los-Habitos-de-los-usuarios-de-Internet-en-Mexico-2018/lang,es-es/?Itemid= BBC (2017). Por qué a partir de ahora para obtener una visa para entrar a EE.UU. tendrás que dar tu información de Facebook y otras redes sociales. Obtenida el 13 de mayo del 2018 de: https://www.bbc.com/mundo/noticias-40161271 
Broderick, R. y Arredondo, I. (2018). Conoce al rey de las fake news en México. BuzzfeedNews.

Recuperado de: https://www.buzzfeed.com/mx/ryanhatesthis/meet-the-millennial-trying-tobecome-the-king-of-mexican-1

Constante, A. (2013). Las redes sociales, una manera de pensar el mundo. México: UNAM Ediciones Sin Nombre

Derrida, J. (2000). La hospitalidad. Buenos Aires: Ediciones de la Flor.

Facebook (2018). Condiciones del servicio. Recuperado de: https://www.facebook.com/legal/terms

Foucault, M. (1979). El ojo del poder en el panóptico. Madrid: Ediciones La piqueta

Foucault, M. (2000). Los anormales. Buenos Aires: Fondo de Cultura económica de Argentina

Foucault, M. (2002). Historia de la sexualidad. Voluntad del saber. Buenos Aires: Siglo veintiuno editores

Foucault, M. (2004). El nacimiento de la clínica: Una arqueología de la mirada clínica. Buenos Aires: Siglo XXI, Editores

Foucault, M. (2005a). Poder psiquiátrico, Curso en el Collège de France (1973-1974). Argentina: Fondo de cultura económica de Argentina

Foucault, M. (2005b). Vigilar y Castigar. Nacimiento de la prisión. México: Siglo XXI Editores.

García, L. (2011). ¿Qué es un dispositivo? Foucault, Deleuze, Agamben. Revista de filosofía: A Parte Rei. (74)

Girard, R. (2009). La anorexia y el deseo mimético. Barcelona: Marbot Ediciones.

Godínez, A. (2018). Filosofía política y subjetividad: aportaciones de una genealogía del deseo. México: Universidad de Guadalajara

IBM (2019). ¿Qué es el Big Data? Obtenido el 3 de julio del 2019 de:

https://www.ibm.com/developerworks/ssa/local/im/que-es-big-data/index.html

Llamas J. y Llamas I. (2018). Internet ¿Arma o herramienta? México: Universidad de Guadalajara Peña, P. (2015). ¿Quién le puede decir que no a Google y a Facebook? Derechos Digitales. Recuperado de: https://www.derechosdigitales.org/9014/quien-le-puede-decir-que-no-agoogle-y-facebook/ 
Ornicar (1977) Entrevista: El juego de Michel Foucault. Revista Ornicar (10), pp. 62. [Versión traducida por Rubio, J. (1978) Revista Diwan. (2 y 3) pp. 171-202] Recuperado de:

https://forofarp.org/images/pdf/Dialogo\%20con\%20otros\%20discursos/MichelFoucault/ElJu egoDeMichelFoucault.pdf

Proceso (2016). Las redes sociales, vértigo y pasión. Revista Proceso Edición Especial (53. Año 39). Grupo Editorial Televisa.

Yehya, N. (2008). Tecnocultura, El espacio íntimo transformado en tiempos de paz y guerra. México: Tusquets Editores. 